\title{
Situation of COVID-19 Pandemic in South Asia
}

\author{
Hom Nath Chalise ${ }^{1,2}$ Krishna Prasad Pathak ${ }^{3}$ \\ ${ }^{1}$ Faculty Member, Department of Public Health, Nobel College affiliated to Pokhara University, Sinamangal, Kathmandu, Nepal \\ ${ }^{2}$ Vice President, Population Association of Nepal, Kathmandu Nepal \\ ${ }^{3}$ Faculty Member, Nepal Open University, Lalitpuar, Nepal
}

\begin{abstract}
:
COVID-19 is spreading all over the world. Latest data shows cases of COVID-19 are increasing rapidly in developing countries. South Asia is also one of such regions where the cases are increasing rapidly. South Asia is less prepared to fight with COVID-19 pandemic due to poverty, poor health care facilities and lowest number of physicians per capita (less than 1). The COVID-19 death rates are interestingly low in South Asia when compared with other regions. But, as the numbers of cases are increasing rapidly and governments are not able to increase the health care facilities and health workers accordingly, this region is also one of the vulnerable region if the severe cases of COVID-19 increases. So, each country should focus to strengthen their health care system and proper mental health counseling to people to avoid the potential crisis that lies ahead.
\end{abstract}

Keywords: COVID-19, Coronavirus,SARS-CoV-2 South Asia, South Asian Association for Regional Cooperation (SAARC),

\section{INTRODUCTION}

The coronavirus widely accepted as having originated in and spread from Wuhan, China, is considered by the World Health Organization (WHO) to be a severe acute respiratory syndrome coronavirus 2, or SARS-CoV-2. ${ }^{1}$ Till February 2020, China was the only country mainly affected by Covid-19. Starting from the beginning of March it started to spread rapidly to South Korea, in the second week of March cases increased rapidly to Italy and Spain including other European countries and in the third week of March to United States and other countries too. ${ }^{2}$ On 11 th March 2020, WHO declares COVID-19 outbreaks of a pandemic. ${ }^{3}$ As of 1 st June 2020, there have been more than 6.3 million confirmed cases COVID-19, with 380 thousand deaths and more than 2.9 million recovered. ${ }^{4}$ Slowly, South Asia is also entering the ranks of COVID-19 affected regions. ${ }^{5}$ This paper analyses the COVID-19 situation of eight countries of this region namely India, Pakistan, Bangladesh, Afghanistan, Sri Lanka, Nepal, Maldives, and Bhutan which are also known as the South Asian Association for Regional Cooperation (SAARC) countries.

The first case of COVID-19 in this region was found on 23rd January in Nepal in a Nepali student who returned from Wuhan, China. ${ }^{2,5,6}$ The second country to report COVID-19 was Sri Lanka $^{7}$ on 27 th January and third-country was India ${ }^{8}$ on 30 th January, both the countries have imported the case of COVID-19 from China. Similarly, Afghanistan ${ }^{9}$ acquired the first COVID-19 case on 24th February and Pakistan ${ }^{10}$ reported on 26th Februaryin both countries it was imported from Iran. Bhutan confirmed its first COVID-19 case on 6th March in a US tourist. ${ }^{11}$ Maldives ${ }^{12}$ and Bangladesh ${ }^{13}$ reported the first confirmed the first case of
COVID-19 on 7th March which was imported from Italy. It shows that in the initial phase most of the confirmed cases of COVID-19 were imported from other countries. ${ }^{5}$

As of 31st May, nearly three hundred fifty thousand cases of COVID-19 and nearly eight thousand deaths from COID-19 are reported in this region. ${ }^{14}$ Although COVID-19 was confirmed in Nepal, Sri Lanka, and India as early as in the third week or fourth week of January, the government activities were not very proactive to deal with this disease. As the COVID-19 cases started to spread rapidly in European countries in the middle of March, the government of South Asia regions started to worry as they have also many people returning from these countries. To control the spread of COVID-19 India and Nepal announced lockdown effective from 24th March $^{6,8}$ and later other countries of this region also followed. Afghanistan, Bangladesh, Pakistan, and Maldives have implemented partial lockdowns, Sri Lanka has responded with quarantine curfews. Countries have also instituted various levels of restrictions on international travel; some countries have completely sealed off their land borders and grounded most international flights. ${ }^{5}$

The table below shows the trend of COVID-19 cases and casualties in South Asia from April 1 to May 31 in three points in time. As of April 1, the total number of COVID-19 cases in

Correspondence: Dr. Hom Nath Chalise, Department of Public Health, Nobel College affiliated to Pokhara University, Sinamangal, Kathmandu, Nepal. Email: chalisehkpp@gmail.com. 
south Asia was 3649 with total deaths 71 and Pakistan has the highest (1865) number of cases reported. On May 1, the total number of cases were 62895 and total deaths in 1772, India has the highest (35043) number of COVID-19 cases. As of May 31, the total number of COVID-19 cases increased to 318910 and deaths also reached $7577 .{ }^{14}$ In the last one month, there were more than 5 times an increase in the number of COVID-19 infected people in this region and the increase was more than
27 times in Nepal. So, far only 43 cases of COVID-19 and no mortality are reported in Bhutan. ${ }^{10}$ Bhutan seems to be the success to control the COVID-19 to some extent. On the other hand, $42 \%$ of infected cases are found recovered in South Asia and recovery rate is satisfactory in Sri Lanka (49\%) and India $(48 \%)$ as of May $31 .{ }^{4}$ Further analysis of data shows the death rate of an infected person from COVID-19 is $2.38 \%$ in this region and the highest is found in India which is $2.83 \%$.

Figure 1: COVID-19 Daily New Cases in South Asia: South Asian Association for Regional Cooperation (SAARC) Region

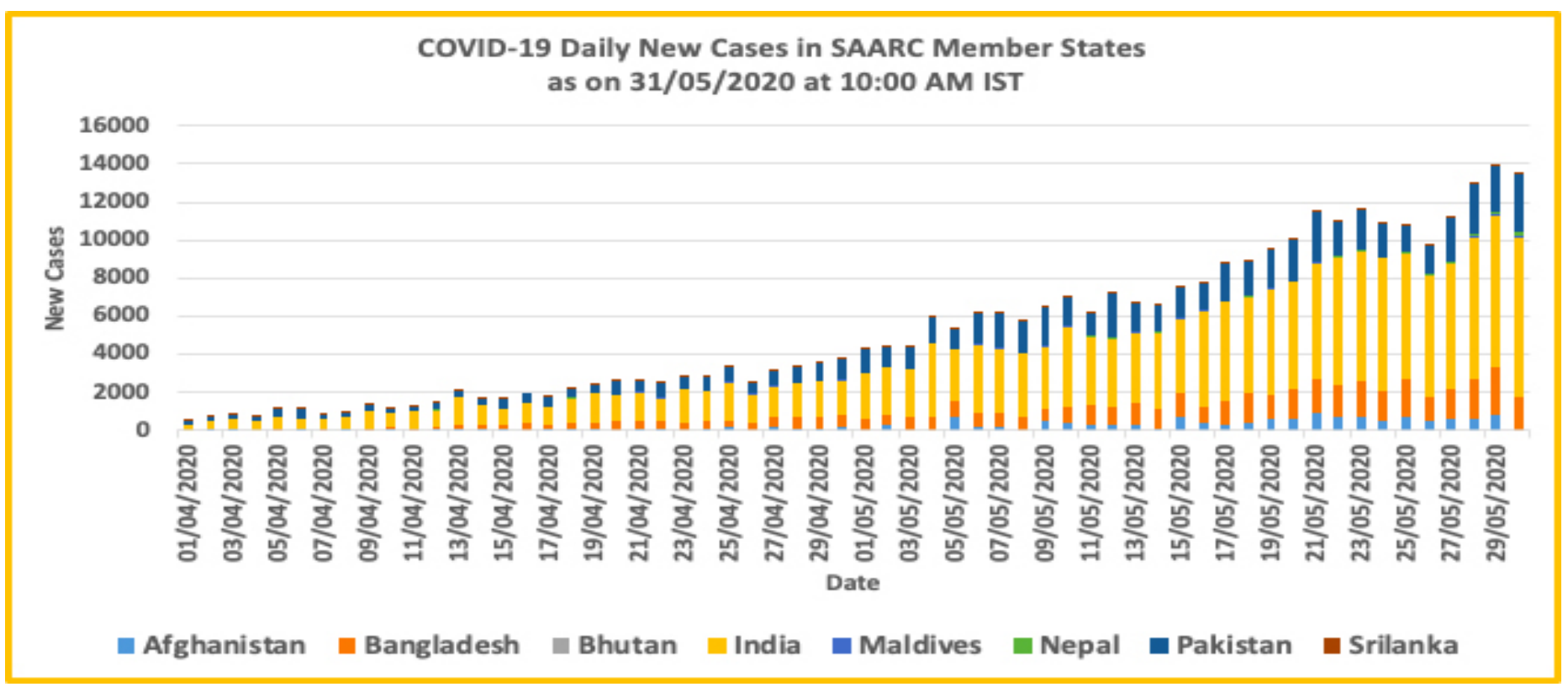

Source: SAARC Disaster Management Center ${ }^{14}$

India is leading in terms of the number of COVID-19 confirmed cases and deaths, followed by Pakistan, Bangladesh, Afghanistan, Maldives Sri Lanka, Nepal, and Bhutan. ${ }^{14}$ India has more than 180 thousand COVID-19 confirmed cases which are around $60 \%$ of this region. The total number of death is also highest in India (5164), which is more than two-third deaths of South Asia. Bhutan has reported no death till 31 May. The number of cases is 1567 in Nepal, but as there are numerous pores between Nepal and India border, the number of cases is increasing rapidly in Nepal as the people coming from India are increasing. ${ }^{2,5,15}$ It is expected to increase more rapidly with the increase of Nepalese workers returning from India and other countries. ${ }^{5}$ The diagram shows the trend of daily cases of COVID-19 cases in the countries of this region.

South Asia is one of the world's poorest and most populous regions. Countries of this regions host nearly 21 percent of the world population, ${ }^{14}$ with a high population density when compared with western countries. ${ }^{16}$ The health care facilities of this region are also very weak. ${ }^{17}$ Each of South Asia's eight countries has one of the lowest numbers of physicians per capita. It ranges from 0.3 physicians per 1,000 people (Afghanistan) to just one physician per 1,000 people (Maldives, Pakistan, and Sri Lanka). ${ }^{18}$ At the best of times, there are too few healthcare workers with negligible resources. Due to such reasons, this region will still be much more vulnerable if the severe cases of COVID-19 increase. ${ }^{17}$

The COVID-19 infection and death rates are interestingly low in South Asia which is one of the most densely populated and economically poor countries. Less number of COVID-19 cases may be due to less testing. ${ }^{17}$ But the latest COVID-19 casualties' death shows still the death is quite low in South Asia compared to western countries. No one knows the exact reason why there is low mortality in this region. People have some assumptions for this, which are not sufficient to prove. First, warmer and humid weather in the South Asian region tempered the spread of the disease. Second, tuberculosis vaccine Bacillus Calmette-Guérin (BCG) may have lowered the impact of COVID-19. ${ }^{19}$ Third, a potentially better immune response among those in the Indian subcontinent and variations in immune response in South Asians are exposed to more germs and infections response in daily life. ${ }^{20}$ Further, Strict lockdown and the young population may be one reason for low mortality in South Asia. ${ }^{17}$ Many countries 
have $5-8 \%$ of their populations aged over 60 and $2-3 \%$ aged over $70 .{ }^{21}$ This compares with Italy's age distribution of about $16 \%$ aged over 60 , and $10 \%$ aged over 70 . Statistics show around $85-90 \%$ of Covid-19 deaths is on the age group over $60 .{ }^{22}$ Due to low life expectancy, there is low number of elderly population in South Asia. Generally, elderly are high vulnerable to COVID-19 related deaths due to low immune system. ${ }^{1}$ A study from Nepal shows less than four percent of people 60 years and older infected from COVID-19 and most of the people who died from COVID-19 are young people. ${ }^{5}$

COVID-19 has created so many mental and psychological health issues. ${ }^{17,22}$ With the recent increase, COVID-19 cases along with an increasing number of deaths have also increased the fear among the people who were in long lockdown. One study found the long prevalence of this pandemic has created different types of psychological disorders and chaos among Nepalese people. ${ }^{23}$ Media and some publications have also reported some cases of suicide in this region. ${ }^{17}$ Some people are already in stress as they are facing the problem of hands to mouth as there is no regular work. Further many cases of COVID-18 are said to be asymptomatic, ${ }^{5}$ it has also made it difficult to identify the people with COVID-19 symptoms and created the fear that it may easily transfer to each other.

Finally, Covid-19 cases are increasing rapidly in South Asia. Countries of this region are criticized that not enough tests were conducted due to extremely limited diagnostic testing; the region may not have sufficient information to gauge the true extent of the epidemic. Further, weak health-related infrastructure and poverty of this region make this region more vulnerable to control COVID-19. Social distancing message should be understood properly and there should not be social isolation. Social counseling and social therapy-related activities maintaining physical distancing should be carried out to minimize the psychological disorders and chaos among people. Although this region still seems less affected by pandemic each country should focus to strengthen their health care system to avoid the potential crisis that lies ahead.

Table1: Situation of COVID-19 in South Asia, 1st April, 1st May and 31st May, 2020

\begin{tabular}{|c|c|c|c|c|c|c|c|}
\hline \multirow{2}{*}{ Country } & \multicolumn{2}{|c|}{$4 / 1 / 2020$} & \multicolumn{2}{|c|}{$5 / 1 / 2020$} & \multicolumn{2}{|c|}{$5 / 31 / 2020$} & \multirow{2}{*}{$\begin{array}{l}\text { First case } \\
\text { reported }\end{array}$} \\
\hline & Cases & Death & Cases & Death & Cases & Death & \\
\hline Afghanistan & 166 & 4 & 2171 & 64 & 15205 & 257 & February 24 \\
\hline Bangladesh & 51 & 5 & 7667 & 168 & 47153 & 650 & March 7 \\
\hline Bhutan & 4 & 0 & 7 & 0 & 43 & 0 & March 5 \\
\hline India & 1397 & 35 & 35043 & 1147 & 182143 & 5164 & January 30 \\
\hline Maldives & 18 & 0 & 468 & 1 & 1672 & 5 & March 7 \\
\hline Nepal & 5 & 0 & 57 & 0 & 1567 & 8 & January 23 \\
\hline Pakistan & 1865 & 25 & 16817 & 385 & 69496 & 1483 & February 26 \\
\hline Sri Lanka & 143 & 2 & 665 & 7 & 1631 & 10 & January 27 \\
\hline Total & 3649 & 71 & 62895 & 1772 & 318910 & 7577 & \\
\hline
\end{tabular}

Source: SAARC COVID-19 situation report 13, 43 and 72

\section{REFERENCES}

1. Chalise HN and Rosenberg E. COVID-19 and the Elderly: Why Does the Immune System Matter? J Inf Dis Trav Med 2020, 4(S1): 000S1-003.

2. Chalise HN. COVID-19 situation in Nepal. Arch PsychiatrMent Health. 2020; 4: 033-034. DOI: 10.29328/ journal.apmh. 1001015

3. World Health Organization. WHO announces COVID-19 outbreak a pandemic. 2020 [5th May, 2020]. Available from http://www.euro.who.int/en/health-topics/healthemergencies/coronavirus-covid-19/news/news/2020/3/ who-announces-covid-19-outbreak-a-pandemic
4. Worldometer. COVID-19 coronavirus pandemic. 2020 [1st June, 2020]. Available fromhttps://www.worldometers. info/coronavirus/?

5. Chalise HN, Dhungana HN. Fears of COVID-19 catastrophe as Nepal reports death from new Coronavirus.J Phys Med RehabilDisabil. 2020; 6: 047. DOI: 10.24966/PMRD8670/100047

6. Ministry of Health and Population, Government of Nepal. Ministry of Health and Population, Nepal's latest Update on COVID-19. 2020 [1st June, 2020]. Available fromhttps:// covid19.mohp.gov.np/\#/

7. Sri Lanka situation, Epidemiology Unit, Ministry of health. 2020 [1st June, 2020]. Available fromhttp:// www.epid.gov.lk/web/index.php?option $=$ com 
content\&view $=$ article \&id=225\&Itemid=487\&lang=en, Accessed on 1st June,2020.

8. Ministry of Health and family welfare, India. 2020 [1st June, 2020]. Available fromhttps://www.mohfw.gov.in/.

9. Mousavi SH, Shah J, Giang HTN, Al-Ahdal TMA, Zahid SU, Temory F, et al. The first COVID-19 case in Afghanistan acquired from Iran. Lancet Infect Dis.2020 .doi: 10.1016/ S1473-3099(20)30231-0.

10. Government of Pakistan. 2020 [1st June, 2020]. Available fromhttp://covid.gov.pk/

11. Ministry of Health, Royal Govt. of Bhutan. 2020 [8 May, 2020]. Available fromhttp://www.moh.gov.bt/"Bhutan confirms first coronavirus case". The Economic Times. 6 March 2020.

12. COVID-19 local updates Ministry of health republic of Maldives. 2020 [1st June, 2020]. Available fromhttps:// covid19.health.gov.mv/en/

13. Covid-19 Status Bangladesh. Institute of Epidemiology, Disease Control and Research (IEDCR).2020 [1st June, 2020]. Available fromhttps://www.iedcr.gov.bd/

14. SAARC disaster management center, coronavirus disease (COVID-19) SAARC Region. 2020 [1st June, 2020]. Available fromhttp://www.covid19-sdmc.org/

15. Chalise HN. COVID-19 situation and challenges of Nepal.Asia Pac J Public Health.2020; 1-2. DOI: 10.1177/1010539520932709

16. World Bank. Population density (people per sq. $\mathrm{km}$ of land area).2020 [25 May, 2020]. Available fromhttps://data. worldbank.org/indicator/EN.POP.DNST

17. Chalise HN. South Asia is more vulnerable to COVID-19 pandemic. Arch PsychiatrMent Health. 2020; 4: 046-047. DOI: 10.29328/journal.apmh.1001018

18. World Bank. Physicians (per 1,000 people).2020 [25 May, 2020]. Available fromhttps://data.worldbank.org/indicator/ SH.MED.PHYS.ZS

19. The Economic times. BCG Vaccination Policies Make a Ten Times Difference in Covid-19 Incidence, Mortality: New Study." The Economic Times. 2020 [1st May, 2020]. Available fromhttps://m.economictimes.com/industry/ healthcare/biotech/healthcare/nations-without-bcgvaccination-saw-higher-cases/articleshow/74956201.cms.

20. Brewster D. Why South Asia may come out of Covid-19 crisisbetter than many expect.2020 [5 May, 2020]. Available fromhttps://www.lowyinstitute.org/the-interpreter/whysouth-asia-may-come-out-covid-19-crisis-better-manyexpect

21. Population Reference Bureaue. World Population Data sheet 2019. Available fromhttps://www.prb.org/worldpopdata/

22. Xiang YT, Yang Y, Li W, Zhang L, Zhang Q, Cheung T, et al. Timely mental health care for the 2019 novel coronavirus outbreak is urgently needed. Lancet Psychiatry, 2020; 7 : 228-229.

23. The Himalayan Times. Psychosocial problems due to COVID-19 and coping mechanisms. The Himalayan Times, Kathmandu, Nepal.2020 [1st May, 2020]. Available from https://thehimalayantimes.com/ opinion/psychosocial-problems-due-to-covid-19and-coping-mechanisms/?fbclid=IwAR 1 mUISwSaNGgfZpdbjaNcJ1TRzu-hYgI9Wg5X9UexEwtsoxwyP6LnsQ 